\title{
Input-to-state stability for infinite-dimensional systems
}

\author{
Birgit Jacob ${ }^{1}$ - Andrii Mironchenko ${ }^{2}$ Felix Schwenninger ${ }^{3,4}$
}

Published online: 14 August 2021

(C) The Author(s) 2021

The notion of input-to-state stability (ISS) was introduced by E. D. Sontag for nonlinear finite-dimensional systems in the late 1980s. ISS unified the Lyapunov and input-output stability theories and influenced the constructive nonlinear control theory for finite-dimensional systems. It has played a major role in the robust stabilization of nonlinear systems, design of robust (in terms of errors in measurements and/or quantization) nonlinear observers, nonlinear detectability, stability of nonlinear large-scale networks, nonlinear sample data and event-triggered control, stability of networked control systems, supervisory adaptive control, and many other areas.

An infinite-dimensional system is a system which can be formulated mathematically as an equation on an infinite-dimensional vector space. In particular, partial differential equations, partial differential algebraic equations, stochastic partial differential equations, delay equations, integro-differential equations and combinations thereof are in this class. Thus, a wide variety of phenomena such as heat transfer, acoustics, electrostatics, electrodynamics, fluid dynamics, population dynamics, elasticity, or quantum mechanics can be formalized in terms of infinite-dimensional systems.

This topical collection presents recent progress in input-to-state stability for infinitedimensional systems and provides an overview of various techniques employed in

Birgit Jacob

bjacob@uni-wuppertal.de

Andrii Mironchenko

andrii.mironchenko@uni-passau.de

Felix Schwenninger

f.1.schwenninger@utwente.nl

1 School of Mathematics and Natural Sciences, University of Wuppertal, IMACM, Gaußstraße 20, 42119 Wuppertal, Germany

2 Faculty of Computer Science and Mathematics, University of Passau, Innstraße 33, 94032 Passau, Germany

3 Department of Applied Mathematics, University of Twente, P.O. Box 217, 7500 AE Enschede, The Netherlands

4 Department of Mathematics, University of Hamburg, Bundesstr. 55, 20146 Hamburg, Germany 
this field. These encompass methods from nonlinear control, operator and semigroup theory, Lyapunov theory, nonlinear networks, and partial differential equations (PDEs).

Funding Open Access funding enabled and organized by Projekt DEAL.

Open Access This article is licensed under a Creative Commons Attribution 4.0 International License, which permits use, sharing, adaptation, distribution and reproduction in any medium or format, as long as you give appropriate credit to the original author(s) and the source, provide a link to the Creative Commons licence, and indicate if changes were made. The images or other third party material in this article are included in the article's Creative Commons licence, unless indicated otherwise in a credit line to the material. If material is not included in the article's Creative Commons licence and your intended use is not permitted by statutory regulation or exceeds the permitted use, you will need to obtain permission directly from the copyright holder. To view a copy of this licence, visit http://creativecommons.org/licenses/by/4.0/.

Publisher's Note Springer Nature remains neutral with regard to jurisdictional claims in published maps and institutional affiliations. 